\title{
Yeni Çağın Hammaddesi Veri Madenciliğinin Sosyolojik Açıdan Değerlendirilmesi
}

\author{
Emine ERDAL
}

Yüksek Lisans Öğrencisi, Necmettin Erbakan Üniversitesi, Sosyal Bilimler Enstitüsü, Sosyoloji Anabilim Dalı, Konya, Türkiye, Eminerdl18@gmail.com

\section{Türkan PAPUŞCUOĞLU}

Yüksek Lisans Öğrencisi, Necmettin Erbakan Üniversitesi, Sosyal Bilimler Enstitüsü, Sosyoloji Anabilim Dalı, Konya, Türkiye, papuscuogluturkan@gmail.com

\begin{tabular}{|c|c|}
\hline Makale Bilgileri & ÖZ \\
\hline $\begin{array}{l}\text { Makale Geçmişi } \\
\text { Geliş: } 16.03 .2021 \\
\text { Kabul: } 30.06 .2021 \\
\text { Yayın: } 30.06 .2021 \\
\text { Anahtar Kelimeler: } \\
\text { Büyük veri, } \\
\text { panoptikon, } \\
\text { simülasyon, veri, veri } \\
\text { güvenliği, veri } \\
\text { madenciliği, toplum } \\
\text { 5.0. }\end{array}$ & $\begin{array}{l}\text { Gelişen teknolojilerle birlikte her geçen gün dijitalleşen hayatın temel unsurları da değişip dönüşmektedir. } \\
\text { Bugünün şartları göz önünde bulundurulduğunda internet üzerindeki her bir hareketi ifade eden veri, merkezi } \\
\text { bir konuma gelmekte ve bu doğrultuda önemi açığa çıkmaktadır. Bunun için artan verilerle birlikte büyük veri } \\
\text { ortaya çıkarken, verilerin kullanılıp analiz edilmesiyle de veri madenciliği gelişmiş ve hemen her alanda } \\
\text { kullanılmaya başlanmıştır. Veri madenciliğinin kullanımı her ne kadar teknoloji temelinde gerçekleşse de } \\
\text { etkileri sosyolojik boyutlar içermekte ve meseleyi sosyolojik açıdan ele almayı da mümkün kılmaktadır. Bu } \\
\text { açıdan makalede veri madenciliği nedir? Veri madenciliğinin toplumsal açıdan olumlu ve olumsuz tarafları } \\
\text { nasıl değerlendirilebilir? Sosyolojik açıdan bu sürece nasıl yaklaşılmalıdır? Gibi soruların cevabı aranacaktır. } \\
\text { Bu doğrultuda hem Michel Foucault hem de Jean Baudrillard’ı çalışmaları bize yol göstermekte, meseleyi } \\
\text { farklı bir açıdan okuma imkânı sunmaktadır. Çünkü veri madenciliği sadece verilerin depolanmasını } \\
\text { içermemekte bununla birlikte depolanan verilerin kullanım ve yönetimi üzerine birçok sorunu beraberinde } \\
\text { getirmektedir. Böylece okuyucuya veri madenciliği üzerine çift yönlü bir bakış gösterilirken olumlu-olumsuz } \\
\text { çeşitli sonuçları da bir arada vermekteyiz. Bu noktada makalede güncel bir mesele yeni bir boyutta ele alarak } \\
\text { tartışılmaktadır. }\end{array}$ \\
\hline
\end{tabular}

\section{Sociological Evaluation of Data Mining as the Raw Material of New Age}

\begin{tabular}{ll}
\hline Article Info & ABSTRACT \\
\hline $\begin{array}{l}\text { Article History } \\
\text { Received: } \quad 16.03 .2021\end{array}$ & $\begin{array}{l}\text { With the developing technologies, the basic elements of life that are digitalized day by day are also changing } \\
\text { and transforming. Considering today's conditions, data that expresses every movement on the internet comes to } \\
\text { accepted: } 30.06 .2021 \\
\text { a central position and its importance in this direction becomes clear. For this, while big data emerged with } \\
\text { increasing data, data mining was developed with the use and analysis of the data and started to be used in almost } \\
\text { every field. Although the use of data mining is based on technology, its effects include sociological dimensions } \\
\text { and make it possible to deal with the issue from a sociological perspective. In this respect what is the point of } \\
\text { the data mining in this article? How can the positive and negative aspect of data mining be evaluated? How } \\
\text { should this process be approached from a sociological perspective? Questions like these will be answered. In } \\
\text { this direction, the works of both Michel Foucault and Jean Baudrillard guide us and offer the opportunity to } \\
\text { read the issue from a different perspective. Because data mining does not only involve the storage of data, but } \\
\text { Big data, data, data } \\
\text { mining, data }\end{array}$ \\
$\begin{array}{l}\text { also brings many problems on the use and management of the stored data. Thus, while showing the reader a } \\
\text { two-sided view on data mining, we also present various positive and negative results together. At this point, a } \\
\text { panopticon, } \\
\text { simulation, society } \\
\text { current issue is discussed in a new dimension in the article. }\end{array}$
\end{tabular}

Atıf/Citation: Erdal E. Papuşcuoğlu T. (2021). Yeni Çağın Hammaddesi Veri Madenciliğinin Sosyolojik Açıdan Değerlendirilmesi Medeniyet ve Toplum Dergisi, 5(1), 66-75.

"This article is licensed under a Creative Commons Attribution-NonCommercial 4.0 International License (CC BY-NC 4.0)" 


\section{GÍRIŞ}

İçinde bulunduğumuz dönem hızlı ve etkili değiş̧imlere sahne olmaktadır. Bu değişim özellikle teknolojik alanlarda gelişmeye başlamıştır. Yapay zekâ, nesnelerin interneti, robotlaşma, 3D yazıcılar, bulut teknoloji ve veri madenciliği gibi teknolojiler endüstriyel faaliyetlere yeni bir alan açmıştır. Endüstri 4.0 olarak adlandırılan bu süreç bunlar ve benzeri daha fazla teknolojiyi bünyesinde barındırmaktadır. Fakat yaşanan bu gelişmeler endüstriyel alanda yoğunlaşsa bile toplumsallıkla doğrudan bağlantılıdır ve onunla birlikte hareket etmektedir. Çünkü endüstri 4.0 yani dördüncü sanayi devrimi temelde bilgi iletişim teknolojileri ve siber fiziksel sistemlerden oluşmaktadır. Bilgi iletişim teknolojileri bu süreçte kullanıcı katılımı temelinde anlık, hızlı ve anlamlı bilgilerin toplanması ve analiz edilmesiyle oluşmaktadır. (Saraçel ve Aksoy, 2020: 28). Yani endüstri 4.0'ın en önemli ayağını toplumsal iletişim ve etkileşim oluşturmaktadır. Dolayısıyla bireyler bu devrime bilinçli ya da bilinçsiz direkt olarak katılmaktadır. Toplumsal hayatı bu sürece dâhil eden ise "veri"dir. Başka bir ifadeyle veri madenciliği bu sürecin hammaddesini oluşturmaktadır.

Toplumsal etkileşimle birlikte siber alandan elde edilen veriler siber fiziksel sistemler aracılığıyla fiziksel alana yani üretime entegre edilmektedir. Bu entegrasyonun amacı kişisel istekler ve tercihler göz önüne alınarak hızlı, etkin ve verimli üretim gerçekleştirmektir. Yani daha kişiselleştirilmiş ürünler üretilerek esnek bir üretim tarzı benimsenmektedir. (Saraçel ve Aksoy, 2020: 28-31). Bu süreç endüstri 3.0'da da ön plandadır. Yani endüstri 3.0 post-fordist üretim anlayışını benimsemiş ve kitlelere hitap eden tek tip üretim yapmaktan ziyade farklılıklar ön plana çıkmış, çeşitlilik artmış ve farklı kesimden bireyler için farklı ürünler üretilmiştir. Bu dönemdeki tartışmalarla kıyaslandığında endüstri 4.0'ın da benzer tartışmaları yaptığı görülecektir. Fakat endüstri 4.0'ın farkı bigdata adı verilen veri madenciliğinde yatmaktadır. Bu süreçte "an" ve "hız" kavramları ön plana çıkmaktadır. Daha açık bir ifadeyle insanların siber alanlarda anlık olarak ürettiği veriler dikkate alınarak hızlıca üretime entegre edilmesi söz konusudur. Ayrıca bu süreç firmaların ayakta kalabilmeleri için hayati bir öneme sahiptir. Çünkü anlık ve hızlı veri sağlayabilen, bunları değerlendirebilen ve üretime dahil eden firma rekabet ve güç avantajına sahip olmaktadır.

Dolayısıyla burada dikkatleri üzerine çeken unsur veridir. sanay 4.0'ın işleyiş mantığı açısından bakıldığında veri, üreticiler için büyük öneme sahipken sosyal bilimler açısından oldukça tartışmalı bir konumdadır. Sosyolojik açıdan veri madenciliği Michel Foucault'un panoptikon kavramıyla veya Jean Baudrillard'ın simülakrlar ve simülasyon teorisiyle değerlendirilebilir. Bu alandaki tartışmalar ise genel olarak veri madenciliğinin denetim mekanizması haline gelmesi veya Baudrillard açısından insanların simülasyon içerisinde yaşaması şeklinde izah edilebilir. Fakat resme daha büyük bir açıdan baktığımızda endüstriyel alanda yeni bir devrim yaşanmakta, toplum 5.0 olarak adlandırılan yeni bir toplumsal döneme girilmekte, sosyal hayat hızla değişmekte ve toplumsal hayat baştan sona yeni kurallarla yeniden inşa edilmektedir. Dolayısıyla buradaki tartışmaları daha geniş bir objektiften değerlendirmek oldukça elzemdir. Veri madenciliği özelinde düşündüğümüzde insanların sürekli kayıt altına alınarak denetlenebileceği, kontrol edilebileceği açısından karamsar bir şekilde duruma yaklaşmak mümkündür. Fakat diğer taraftan veri madenciliği ile teknolojik gelişmelerin daha hızlandığını ve her açıdan değişim ve dönüşümün gerçekleşeceği yeniçağın en önemli unsuru olarak da değerlendirilebilir. Dolayısıyla bu makalede veri madenciliği nedir? Veri madenciliğinin toplumsal açıdan olumlu ve olumsuz tarafları nasıl değerlendirilebilir? Sosyolojik açıdan bu sürece nasıl yaklaşılmalıdır? Gibi soruların cevabı aranacaktır. Aynı zamanda bu makalenin amacı veri madenciliğinin ve yeni gelişen teknolojilerin sosyolojik etkilerini incelemektir. Buna ek olarak hızlı gelişmelerin ve değişmelerin olduğu bu dönemde, teknolojik gelişmelerle sosyal hayat arasındaki farkı en aza indirmektir. Çünkü Durkheim'in de ifade ettiği gibi hızlı toplumsal değişimlerin yaşandığı dönemlerde anomi ortaya çıkabilir. Dolayısıyla toplumda anomi, bunalım veya kaos gibi durumlar gerçekleşmeden yeni dönemi tanımak, anlamak ve stratejiler üretmek toplum sağlığ için oldukça önemlidir.

Tüm bunlar göz önüne alındığında veri ve veri madenciliğini sosyolojik açıdan ele almanın 
önemi ortaya çıkmaktadır. Fakat konunun sosyolojik boyutunu anlamanın da ancak teknoloji, bilişim ve mühendislik temelinden hareketle olacağı da açıktır. Bu doğrultuda veri, veri bilimi ve veri madenciliği konularında yazılmış temel eserlere bakmak yararlı olacaktır.

U. Tuğba Şimşek Gürsoy Veri Madenciliği ve Bilgi Keşfi (2009) kitabında verilerin depolandığı veri ambarlarından veri madenciliğine pek çok konuyu irdelemekte, bu ikisi arasındaki ilişkilere değinmektedir. Veri madenciliği süreçlerini ele aldığ gibi veri madenciliği modellemeleri ve uygulama alanlarını da açıklar. Bunlara ek olarak istatistik ve çeşitli analiz yöntemlerinin de sunulduğu kapsamlı bir çalışmaya imza atar. Gökhan Satıroğlu da Veri Madenciliği Kavramlar ve Algoritmaları (2013) kitabıyla konuya dair Türkçe literatüre önemli bir katkı sunmaktadır. Satıroğlu'nun kitabı yeni başlayanlar için olduğu gibi aynı zamanda da deneyimliler için de yol gösterici niteliktedir. Çünkü veri madenciliği, veri modellemeleri, sınıflandırma ve kümeleme gibi çeşitli bölümlerle konu detaylı bir analizle sunulmuştur. Bunlarla birlikte üç ayrı yazılımın tanıtıldığı kitap kendi yazılımını geliştirmek isteyenler için de faydalı görünmektedir.

M. Erdal Balaban, Elif Kartal ile kaleme aldığ Veri Madenciliği ve Makine Öğrenmesi Temel Algoritmaları ve $R$ Dili Ille Uygulamaları (2015) eserinde veri konusunu yapay zekâlar ve makine öğrenme ekseninde tartışmaktadır. Bu açıdan kitaba yapay zekâ tartışmalarının dâhil edilmesiyle birlikte konunun daha da zenginleştirildiği söylenebilir. Yapay zekâların sahip olduğu bulanık mantıklar ve makine öğrenme ile daha çok verinin elde edildiği süreçlerde veriden bilgiye giden yolu göstermektedir. Daha sonra da bu verilerin hesaplanması, analiz edilmesi ve görselleştirmelerinin yapılmasını mümkün kılan R dili konusuna geçilmektedir. Birçok arama motoru ve sosyal medyada da kullanılan $\mathrm{R}$ dili uygulamaları ve alanlarının da eklenmesiyle kitap derinleştirilmiştir.

Veri Bilimi (2019) ise Cem Sütcü ile Çiğdem Aytekin'in yazdığı bir eserdir. Yazarlar bu kitaplarında verinin geleceğini gündeme getirmektedir. Yani ortaya çıkan verilerle birlikte nasıl bir geleceğe doğru ilerlendiğini ele alıyorlar. Verinin dönüştürdüğü ve yönlendirmeye başladığı gündelik hayatlara karamsar bir yaklaşımın da olabileceğine işaret ediyor ve bu açıdan okuyucuya verinin olumlu ve olumsuz yönlerini hatırlatıyorlar.

İlker Arslan'ın yazdığı Python İle Veri Bilimi (2019) de günümüzde dikkat çeken eserler arasında sayılmaktadır. Arslan, bu eseriyle birçok alanda kullanılan ve çeşitli kullanım kolaylıkları açısından da popülerlik kazanan Python program dili ekseninde veri konusunu ele almaktadır. Programlama, veri analizi ve yapay öğrenme başlıklı üç bölümden oluşan kitabın bir diğer önemli yanıysa temel bir giriş kitabı niteliğinde olmasıdır. Yani yazar kitabında veri bilimini ele alırken akıcı bir dil kullanmakta ve bu sayede konuyu daha anlaşılabilir hale getirmektedir. Bu doğrultuda da aslında veri bilimine dair araştırma yapmak isteyen pek çok kişinin başvuracağ temel bir kaynak olarak kabul edilmektedir.

Veri ile ilgili bu eserler göz önünde bulundurulduğunda aslında veriyle ilgilenen bir kesimin olduğu gibi bu alanı yeni keşfedecek olan bir kesimin de olduğu anlaşılmaktadır. Yani veri konusu günümüzde giderek ilgiliyle karşılanmakta ve disiplinler arası çalışmalara da uygun görülmektedir. Bu açıdan bahsedilen çalışmalar her ne kadar pozitif bilimler mantığına dayansa da sosyal bilimlere de bir o kadar konu olabilecek niteliktedir. Bu makale ise bu alandaki sosyal bilimler literatürüne katk1 sağlamayı hedeflemektedir. Bir diğer deyişle sosyolojinin geniş konu alanına veri, veri toplumu, veri madenciliği gibi konuları da dâhil ederek hem disiplinler arası bir çalışma ortaya koymakta hem de sosyolojik bakış açışıyla verinin farklı boyutlarını gündeme getirmektedir. Yani verinin ve veri madenciliğinin farklı boyutlarını tartışmaya açarak konuyu sosyolojik kavramlar eksininde yeniden değerlendirmektedir. Böylece çalışmada veri bilimine dair okumalar da sosyolojik çalışmaların eklenmesiyle desteklenmektedir. Bu açıdan çalışma literatüre dayalı olarak teorik bir çerçevede düzenlenmiştir. 


\section{VERİ MADENCILIIĞİNIN TOPLUMSAL HAYATA YANSIMASI}

Teknolojik ilerlemelerle birlikte her geçen gün değişip dönüşen toplumsal hayatın en önemli unsurlarından biri haline gelen veriler hayatımızın her alanında kullandığımız kaynaklardır. Bir insanın gündelik hayatında da kurumsal bir firmanın çalışmalarında da aralarında çeşitli farklılıklar olsa da veriler kullanılmaktadır. Bu açıdan verinin/datanın bilgisine sahip olmak da her geçen gün önem kazanmaktadır.

Dolayısıyla veri (data), gözlemlenen şeylerle ilgili kayıtları gösterir ve çok çeşitli biçimler (örneğin zekâ testlerindeki puanlar, araştırma amaçlı görüşme kayıtları, alan araştırmalarında tutulan günlükler ya da kasete alınmış görüşmeler gibi) alabilir. Bu biçimlerde toplanan kayıtların hepsinde sonuç olarak ortaya veriler (data), yani analiz yoluyla birtakım çıkarsamalar yapılabilmesini sağlayan gözlemler sunulur (Marshall, 2020: 787).

Görüldüğü üzere çeşitli şekillerde elde edilen veriler, üzerinde konuşulabilecek ve bu sayede insan etkinliklerinin faydasına sunulabilecek bilgilere işaret etmektedir. Genel bir çerçeveden verilerin somut maddelere dayandığı ve klasik metotlarla elde edilebileceği düşünülse de bugün içinde bulunduğumuz teknolojik ilerlemelerle internet üzerindeki her bir hareketin de bir veri olduğunu ifade etmek yanlış olmayacaktır. Yani internet üzerinde gerçekleştirdiğimiz her bir tıklama ve görüntüleme bir veriye işaret etmekte ve hâlihazırda milyonlarca veriyi oluşturmaktadır. Söz konusu verilerin günümüz koşulları dikkate alındığında ne denli büyük miktarlarından bahsedileceği dikkatlerden kaçmamaktadır. Diğer bir deyişle bugünün verileri hemen her saniye artmakta ve değişmektedir. $\mathrm{Bu}$ artışın ve değişmenin kaçınılmaz sonucu olarak 'big data' kavramı ortaya çıkmıştır. Büyük veri anlamında kullanılan big data kavramı sadece fiziki bir büyüklüğü ifade etmemekte kavramsal anlamından fazlasını içermektedir. Bilgisayarların işleyemeyeceği kadar büyük olan verilerdir. Bu veri sürekli büyümektedir. Bunun daha güzel bir tanımı $5 \mathrm{~V}$ olarak yapılan tanımdır. $5 \mathrm{~V}$ volume, velocity, variety, veracity ve value'dir (Seker, 2015:10). 5V ise sırasıly şu şekilde açıklanmaktadır: hacim, hız, çeşitlilik, doğruluk ve değer. Bahsedilen $5 \mathrm{~V}$ big datanın temel özelliklerini oluşturmakta ve onu diğer veri çeşitlerinden ayırmaktadır. Çünkü artık söz konusu olan verinin büyüklüğünün yanı sıra onun inanılmazla hızla ve çeşitlilikle oluşmasıdır. İnternet ortamının sunduğu hız ve kaynak çeşitliliği big datayı farklılaştırırken bu verinin doğruluğu ve değeri meselesi de çeşitli tartışmaları beraberinde getirmektedir. Fakat en nihayetinde tartışmaları ve faydaları-zararları kapsamında big data konuşulmakta ve gündem haline gelmektedir. Çünkü big datadan bahsederken sadece onun içeriğinden değil onunla birlikte hayatımıza giren veri madenciliği ve veri güvenliği gibi meselelerden de bahsetmek gerekmektedir.

Veri madenciliği ve veri güvenliği meseleleri de temelde big dataya dayanmakta ve big data sayesinde ortaya çıkmaktadır. 'Büyük Veri' ifadesinin arkasındaki temel fikir, yaptığımız her şeyin giderek daha fazla dijital bir iz (veya veri) bırakmasıdır ki bu bizim (ve başkalarının) bu izleri kullanıp analiz edebilmesidir. Bu nedenle Büyük Veri, toplanan verileri ve bunları kullanma yeteneğini ifade eder. ${ }^{1}$ Yani buna göre büyük veriler doğru bir şekilde kullanılmalarıyla yararlı araçlar olabilmekte ve anlamlı sonuçlara ulaşılabilmektedir. Bu açıdan da veriler üzerindeki etkinliğin ne kadar yüksek olursa o denli doğru sonuçların elde edilebileceği açıktır.

Veri madenciliği konusu temelde çeşitli durumların ve insanların bilgisinin bir veri haline gelmesini ve sürekli olarak kaydedilmesini içermektedir. Günümüzde birçok alanda veri madenciliği ile karşılaşmaktayız çünkü verilerin kaydedilmesi ve değerlendirilmesi sonucunda insanlara yönelik daha uygun kararlar verilmektedir. Daha doğrusu verilerin kullanılması üretici ve tüketiciler için belirli faydalar sağlamaktadır. Veri madenciliğinde önemli olan kısım ne kadar çok veri aktarılırsa yapay zekânın bu veriyi analiz etmesi ve kararlara ulaşmasında o kadar kolay olacak olmasıdır. Veri ${ }^{1}$ Kaynak: https://www.bigdatanews.datasciencecentral.com/profiles/blogs/big-data-explained-in-less-
than-2-minutes-to-absolutely-anyone (Erișim Tarihi: 15 Șubat 2021) 
madenciliğinde biz başat aktör olarak Google'1 görmekteyiz (Erdal ve Papuşcuoğlu, 2018: 12).

Pasajdan da anlaşıldığı gibi Google'ın hayatın her alanında kullanıyor olması ve çok çeşitli bilgilerle onun besleniyor oluşu göz önünde bulundurulursa şüphesiz bu seçimin nedeni anlaşılır olacaktır. Yani Google'ın işleme mantığ zamanlarda da bu bilgilerin yenileriyle ya da benzerleriyle desteklenerek genişletilmesidir. Örneğin bize sunulan reklamların ya da çeşitli haberlerin kaynakları önceki bilgilerimiz ve kullanımlarımıza diğer bir deyişle önceki ve saklanan verilerimize dayanmaktadır. Google kendisine sunulan ve üzerinde gerçekleştirilen tüm hareketleri bir veri olarak kabul etmekte ve herkes için hazırladığ 1 ayrı ayrı dosyalarda saklamaktadır. Buradan hareketle Google'ın büyük bir veri madenine sahip olduğu ve bu verilerini en gelişmiş şekilde kullandığını söylemek yanlış olmayacaktır. Hatta öyle ki Google'ın sunduğu imkânların son derece tutarlı ve şaşırtıcı olması da sıklıkla karşılaşılan bir durumdur. Yani pek çok insanın Google'da arama yapmamasına rağmen araştırmak istediği konularla ilgili reklam ve bildirimler alması yapay zekâların ve veri madenciliğinin boyutları hakkında asparagas söylemleri de ortaya çıkarmıştır. Fakat gelinen noktada eldeki verileri en iyi şekilde analiz eden ve yorumlayan sistemler inkâr edilemez birer gerçektir.

Google'ın yanı sıra çeşitli sosyal medya ağları da verilerin en iyi şekilde kullanıldığı alanlar olarak dikkat çekmektedir. Kişiler bu ağlar üzerinde kendi kimliklerini bir anlamda kendi verilerini kullanıma açmakta ve diğerleriyle etkileşimleri kapsamında da her bir etkinlikleriyle sosyal medyada bir veri oluşturmaktadır. Bu platformlar insanların etkinliklerini veriler haline getirerek mizahtan siyasete kadar çok çeşitli alanlarda kullanabilmekte ve farklı şekillerde yönlendirebilmektedir. Burada her ne kadar bu sistemlerin yararlı sonuçlar ortaya çıkardığı yadsınamazsa da bu durumun çeşitli sorunları da beraberinde getirdiği açıktır. Bu sorunların en başında ise veri güvenliği gelmektedir.

İnternetin hâkim olduğu bu çağda nasıl ki her durumda verilerimiz kullanılıyorsa bu kullanılan verilerin de ne derece korunduğu sorunu gündeme gelmektedir. Çünkü her an her dakika verilerimizi kullanmakta ve hatta onlara yenilerini eklemekteyiz. Bu durumda gerek kişisel gerekse toplumsal sorunlar ortaya çıkabilecektir.

Tüm sistemlerin veriye bağlanması ve bunun savunma, sanayi, sağlık, güvenlik vs. alanlarda kullanılmasıyla verilerin güvende kalması demek ülkenin güvende kalması demektir. Dolayısıla güvenlik tanımının da değiştiğini görmekteyiz. Bir ülkeye saldırmanın hem askeri hem ekonomik birçok yöntemi vardır ve bunlardan en önemlisi verilere saldırılmasıdır yani diğer bir değişle siber güvenliktir. Siber güvenliğin bu kadar önemli olmasının sebebi ise diğer saldırılar belirli bir bölgedeki belirli insanları etkilerken bir ülkenin verilerinin ele geçirilmesi tüm sistemin çökmesine neden olmaktadır. Etkisi bakımından değerlendirdiğimizde atom bombasından daha etkili olduğunu söylemek yanlış olmasa gerek (Erdal ve Papuşcuoğlu, 2018: 21).

Burada görüldüğü üzere güvenlik meselesi söz konusu olduğunda pek çok alandan bahsedildiği gibi bir üst düzeyde ülkenin güvenliği de gündeme gelmektedir. Yani durum sadece kişisel boyutları aşmakta ülkenin ve toplumun güvenliğine de işaret eder hale gelmektedir. Bu durum da verinin ve veri güvenliğinin gelinen noktada önemi açığa çıkarmaktadır. Bu açıdan söz konusu olan sadece veriyi elde etmek ve kullanmak değil verinin güvenliğini de sağlamaktır. Ayrıca sadece veri güvenliğinden bahsetmek de eksik olacaktır. Veri güvenliğinin yanı sıra verilerle birlikte insanların yönlendirilmesi söz konusudur ve yine bu durum verilerin yanıltıcı şekilde kullanılmasıyla oluşmaktadır. İnsanlar her geçen gün sosyal medyanın yönlendirmesiyle hareket etmekte, giderek sanallaşmaktadır. Çünkü hemen her yerden hayatlarımıza dâhil olunmakta ve belirli kategorik düzeylere yerleştirilmekteyiz. Diğer bir ifadeyle verilerimiz bizleri belli bazı konumlara getirmekte o konumlar içerisinde hareketlerimiz belirlenmekte ve yönlendirilmektedir. Böylece hem gerçeklikten kopuş yaşanmakta hem de veriler hayatı kolaylaştırmaya yarayan temel işlevlerinden uzaklaşmaktadır.

Tam bu noktada akla kişisel asistanlar olarak işleyen uygulamalar gelmektedir. Bu uygulamalar gerçek hayatta bir asistanın yerine getireceği işlevleri sanal olarak yapmakta, kullanıcısının hayatını 
kolaylaştırmaktadır. Yani bu asistanlar hem bir yandan kullanıcısının kendisine yüklediği bilgileri işleyerek kullanıcısına hizmet etmekte hem de sanal bir uygulama ile sohbet etme ve bir anlamda sosyalleşme imkânı sağlamaktadır. Buradan anlaşılan ise yakın gelecekte insanların sosyalleşme ortamlarının da değişime uğrayabileceği ve giderek bireyselliğe doğru evirileceğidir. Yani sanal asistanların planlamalar, hatırlatmalar gibi asıl işlevlerini yerine getirirken farklı kullanımları da gündeme gelebilecektir. Bu açıdan insan ilişkileri de giderek sanal ortamlara aktarılarak yürütülecektir. 2013 yapımlı Spike Jonze imzalı Aşk (Her) bilimkurgu filmi bu minvalde bir gelecek ve sanal ilişkilere dair bir örnek sunmaktadır. Toplamda 103 ödülün sahibi film, kariyerli ve modern insanın yalnızlı̆̆ına, ilişki kurma ve sosyallik ihtiyacına yönelik önemli saptamalarda bulunuyor... (Zencirkıran, 2015: 304). Yani sosyal bir varlık olan insanın sosyalliğinin dönüşmesiyle gerçek ve sanalın iç içe geçtiği ve birbirini etkiler hale geldiği görülmektedir. Böylece kişisel asistanlar da işledikleri veriler üzerinden kullanıcılarıyla bir arkadaş gibi etkileşim kurarak hareket edebileceklerdir.

\section{VERI TOPLUMU}

Peki hem bireysel olarak hem de toplumsal ilişkilerde veri kullanıma nasıl yaklaşmalıyız? $\mathrm{Bu}$ soru bir bakıma endüstri 4.0'a ve beraberinde tartışılmaya başlanan toplum 5.0'a nasıl yaklaşmalıyız sorusuyla aynı yönü işaret etmektedir. Yani daha önce de belirttiğimiz gibi veri madenciliğiyle birlikte teknolojiler gelişmekte ve devrimlerden bahsetmekteyiz. Teknolojik inovasyonda öncülük edenler ve özellikle mühendisler veri havuzunun oluşmasıyla birlikte veri analizi ve yorumlanmasında önemli yol kat etmişlerdir. Özellikle veri madenciliği alanının gelişmesi akıllı evler, akıllı fabrikalar, akıllı kentler gibi akıllı sistemlerle donatılmış yeni bir sosyal ve fiziksel sistemin temelini oluşturmaktadır. Oluşan bu ağın gelişimi ve işleyişi yine verinin toplanması ve analiz edilmesiyle gerçekleşmektedir. Daha basit bir şekilde açıklamak gerekirse internet üzerinde gereksiz sayısız veri bulunmaktadır. Bu verilerin hepsiyle direkt olarak kullanıcı muhatap olduğu zaman doğru bilgiye ulaşmak ayrıca bir çalışma gerektirecektir. Fakat veri madenciliği ile kişisel bilgilerin kullanılması ihtiyaç duyulan veya duyulabilecek verilere daha rahat ulaşma imkânı sağlamaktadır. Yani bir arama motorunda ilgili sonuçların çıkması için de kişiler hakkında verilerin toplanması, analiz edilmesi ve yorumlanması gerekmektedir.

"Verinin petrol, altın veya ulusal topraklar olduğunun anlaşılması ve işlenip değer elde edilmesi artık bir zorunluluktur. Tarımdan otomotive, orman yangınlarını kontrol altına almadan gelecek yılın ürün rekolte tahminine, kara ve hava yollarını yönetmeden şehir içi trafiği optimize etmeye, eğitimden inovasyona, akıllı şehirlerin planlanmasından yönetimine, karar destek sistemlerinden zeki sistem modellemeye, kaynak planlamadan ülke yönetimine, otomatik araç kontrolünde hedef izleme ve takip sistemlerine, erken uyarı sistemlerinden otomatik kontrol sistemlerine, konuşma ve konuşmacı tanımadan konuşma ve sohbet sistemlerine, akıllı robotlardan kara fabrikalara..."(Sağıroğlu ve Demizrezen, 2020: 47)

Veriye dayalı geliştirilen teknolojiler toplumsal hayatın her alanına nüfus ederek yeni bir gerçeklik inşa etmektedir. Bu durum veri merkezli bir toplumsal yapı oluşturmaktadır. Dolayısıyla veri odaklı teknolojilerin toplumsal sistemin önemli bir parçası haline gelmesi ise verinin değerini artırmaktadır.

Burada “Veri yeniçağ için neden bu kadar önemli hale gelmiştir?” sorusu karşımıza çıkmaktadır. Veriyi önemli kılan sebeplerinden birisi öngörülebilirlik sağlamasıdır. İçinde bulunulan çağın karmaşık ve belirsiz olması tüketicilerin tercihlerinin hızla değişmesine neden olmaktadır. Kapitalizm açısından düşündügümüzde ise bu kaygan ve belirsiz ekonomik zemin kâr ve büyüme hedefleri önünde büyük bir engel oluşturmaktadır. Diğer taraftan belirsizlik hali kapitalizm bünyesinde gerçekleşen krizleri beslemektedir (Gençoğlu, 2015: 23). Dolayısıyla üreticiler için geleceğin tahmin edilebilmesi hayati bir önem taşımaktadır. Bu durum üretim endüstrisinin kişisel tercihlere odaklanmasını ve daha esnek bir yapıya dönüşmesini gerekli kılmıştır. Böylece veri odaklı yaklaşımlar daha iyi ve daha çabuk kararlar alınması, maliyet tasarrufu sağlanması ve gerçek zamanlı hareket imkânı sunması açısından önemlidir. 
(Schwab, 2020: 157). Bu nitelikler verinin kârı desteklemesi, rekabet avantajı sağlaması, sermaye birikimine olanak tanıması açısından kapitalizmle iç içe olduğunu göstermektedir.

Küreselleşme ve internet ağının herkesi kuşatması aynı zamanda kültürlerin etkileşime girmesine ve farklılaşmanın giderek artmasına neden olmuştur. Böylece tercihlerin ve isteklerin farklılaştı̆̆ını, değiştiğini ve farklı kültürler tarafindan etkilediği görülmektedir. (Turner, 2020: 552557). Dolayısıyla üreticiler için kullanıcıların verilerin toplanması ve analiz edilmesi daha iyi karar verme, etkili pazarlama ve rekabet avantajlarını oluşturmaktadır. Veri madenciliğinin sunduğu tahmin edebilirlikle üreticiler ekonomik belirsizliği bir nevi ortadan kaldırmayı hedeflemektedir.

Diğer taraftan veri madenciliği konusunda en çok tartışılan mevzu verilerin güvenliğidir. Veriler saklanması mevzusu korunması gereken değerli madenler halini almaktadır. Verilerin saldırıya açık olması aynı zamanda kişilerin verilerini sanal ortama yükleyip yüklememe tedirginliğini yaşatmaktadır. Verinin açık olması mahremiyet kaygılarını ve güven problemini de beraberinde getirmektedir. Bunun yanı sıra herhangi bir sorunda yetkili bir makamın bulunmaması da önemli bir problemdir. Schwab bu bakımdan veri üzerinden algoritma savaşlarının olabileceğini vurgulamaktadır. (Schwab, 2020: 157)

Görüldüğü gibi veri madenciliği üreticiler için altın madeni olsa da diğer taraftan tüketiciler için mahremiyet ve güvenlik sorunlarını oluşturmaktadır. Aynı zamanda sürecin nispeten yeni olması ve hızlı gelişmesi nedeniyle oluşabilecek sorunlarda muhatabın bulunmaması gibi hukuksal süreçlerle karşılaşılması oldukça muhtemeldir. Diğer taraftan veri güvenliğinin sağlanabilmesi için kesin bir çözüm yolu da yoktur. Yani verilere sahip olmak hem üreticiler hem de devlet açısından güç olarak görülse bile diğer taraftan büyük bir güvenlik açığını da oluşturmaktadır. Böylece veri güvenliğini bir yerden sonra ulusal güvenlik olarak değerlendirmek mümkündür.

\section{VERİ MADENCILIĞĠININ PANOPTIKON KAVRAMI VE SIMÜLASYON KURAMI EKSENINDE DEĞERLENDİRILMESI}

Genel olarak veri madenciliği, güvenlik ve mahremiyet açısından ele alınmaktadır. Fakat sosyolojik olarak daha farklı temellerde değerlendirmektedir. İlk olarak Foucault'un yeniden yorumladığı panoptikon kavramıyla veri madenciliği arasında ilişki kurmak mümkündür. "Kontrol Evi” anlamına gelen panoptikon “....merkezi bir kontrol kulesi etrafında inşa edilmiş hem kontrol memurunun hem de orada tutulan insanların sürekli gözetlendiği, açık tek 'hücreler'den oluşan daire şeklinde bir yapı.” olarak tanımlanmış ve ilk kez Bentham tarafından kullanılmıştır. Michel Foucault ise Hapishanenin Doğuşu adlı eserinde panoptikonu iktidarın bir aygıtı olarak değerlendirmiş ve insanların bu şekilde gözetlendiğine ve denetlendiğine vurgu yapmıştır. Bir diğer ifadeyle "panoptikon, gözetim altında tutulanların her zaman görülebildiklerinin bilincinde olmalarını sağlaması yüzünden otomatik bir iktidar işlevi görmektedir." (Marshall, 2020: 574). Bu açıdan veri madenciliği değerlendirildiğinde insanların dijital izlerinin sürekli kayıt altında tutulması, kaydedilmesi ve kategorileştirilmesi bir nevi panoptikon işlevi görmektedir. Kayıt altında olan kişiler bunun bilincinde olarak sürekli kendisini denetleyerek iktidarın kurallarına uygun şekilde hareket edecektir. İktidar sahipleri terimini burada geniş çapta firmalar, üreticiler, siyasallar vb. anlamda düşünülmelidir. Şimdi vereceğimiz örnekte kişilerin denetim altına alınmasının adım adım nasıl gerçekleştiğini görebiliriz:

Giyilebilir sağlık cihazları alanında şu anda gerçekleşmekte olan şeyler mahremiyet meselesinin karmaşıklığı hakkında bir fikir verebilir. Artan sayıda sigorta şirketi poliçe sahiplerine şu öneriyi getirmeye hazırlanıyor: eğer sağlık durumunuzu -ne kadar uyuduğunuzu ve egzersiz yaptığınızı, her gün attığınız adımın sayısını, yediğiniz kalorilerin sayısını ve türünü vb.- izleyen bir cihaz kullanmayı ve onun bu enformasyonu sağlık sigortası şirketinize göndermesini kabul ederseniz, sigorta priminizden indirim yapmayı teklif ediyoruz (Schwab, 2020: 115).

$\mathrm{Bu}$ örnekte de görüldüğü gibi verilerin toplanması, analiz edilmesi ve anlamlı bir şekilde yorumlanması kişilerin şimdi ve daha sonraki sağlığı hakkında bilgi vermekte ve sigorta şirketlerine aktarılarak verilere göre sigorta yapılıp yapılmayacağı vs. belirlenmektedir. Bu durum verilere hâkim 
olan kurumların -sigorta şirketleri gibi- insanları kendi istediği gibi yaşamaya, hareket etmeye, tüketmeye zorlamaktadır. Diğer taraftan "insanların sağlığı ve iyiliği için” gibi yorumlar yapılabilir fakat burada kritik olan nokta insanların iyiliğine insanların karar veremiyor oluşudur. Ayrıca toplumsal eşitsizliğin giderek arttığı günümüzde sağlıklı yaşamak bir lüks ve sınıfsal davranış kalıbı haline gelmiştir. Böylece geliri asgari yaşam şartlarına yeten orta ve alt tabakadaki insanların bu ve benzeri uygulamalarda dezavantajlı durumda olacağı açıktır. $\mathrm{Bu}$ örneğin bir başka boyutu ise insanların düşüncelerini temele alan veriler üzerinden gerçekleşmektedir. İnsanlar düşünceleri üzerinden yargılanabilir ve kategorileştirilebilir. Dolayısıyla burada işaret edilen nokta sadece verinin paylaşımı ve analiz edilmesi değildir. Hammadde olarak ele alınan veri analizden sonra geri insana dönmektedir. Analizle birlikte değer kazanan veri bu kez insanın ürettiğinden farklı, hareketlerini ve düşüncelerini değiştiren yeni bir yapıya sahip olmaktadır. Bu döngü aslında çalışmanın da ana noktasını oluşturmaktadır. İlk başta basit olarak ele alınan veri diğer verilerle birleșip ve anlamlı bir şekilde analiz edilince değerli madene dönüşmektedir. $\mathrm{Bu}$ durum aynı altın, elmas gibi diğer değerli madenlerde olduğu gibi toplumsal ilişkilerde belirleyici rol oynamakta ve insan üzerinde, insanı yöneten bir konuma yükselmektedir.

Böylece iktidarın insanları direkt olarak denetlediği mekanizmaların yerine sanki denetlemiyormuş gibi göründüğü ancak bu şekilde yoğun bir denetim ve baskı uyguladığı alanlar gelişmektedir. Ayrıca burada dikkat etmemiz gereken nokta bu durumun sadece kamusal alanda değil özel alanda da devam etmesidir. Yani sadece kamusal alanda iktidar tarafından yürütebilen gözetim ve denetim artık çok rahat bir şekilde özel alanlarda da devam etmektedir. Bu durum insanların özgürlüğünü kısıtlamakta ve insanları verileri toplayan kurumlara bağımlı hale getirmektedir.

Toplumun datalaşmasını simülakrlar ve simülasyon teorisi açısından da değerlendirmek mümkündür. Jean Baudrillard'ın Simülakrlar ve Simülasyon adlı eserinde gerçeklikle ilgili şu pasaja rastlamaktayız:

"Günümüzde gerçek artık minyatürleştirilmiş hücreler, matrisler, bellekler ve komut modelleri tarafindan üretilmektedir. Böylece gerçeğin sonsuz sayıda yeniden üretimi mümkün olmaktadır. Bundan böyle gerçeğin akılcı bir görünüme sahip olmasının anlamı yoktur, çünkü "gerçek" ideal ya da olumsuz süreçlerle başa çıkabilecek (boy ölçüşebilecek) bir durumda değildir. Gerçek artık işlemsel bir görünüme sahiptir. Aslında buna gerçek bile denilemez, çünkü çevresinde onu sarıp sarmalayan bir düşsellik yoktur. Bu atmosferden yoksun bir hiperuzamda kombinatuvar modeller yayan, sentetik bir şekilde üretilmiş gerçek yani hipergerçektir" (Baudrillard, 2018: 14$15)$.

Bu pasajda görüldüğ̈̈ gibi gerçekten bahsedebilmek gittikçe daha zor bir hale gelmektedir. Baudrillard'ın bahsettiği durum gerçeğin yeniden inşa edilmesi ve sahte olanın gerçekten daha gerçekmiş gibi görünmesidir. Televizyon örneği üzerinde duran Baudrillard, en acı olayların bile seyirlik hale gelmesini eleştirerek bir olayın, acının sadece bir simülakr hale geldiğini, gerçeğin ve hislerin ortadan kalktığını işaret etmektedir. Günümüz açısından değerlendirdiğimizde daha ileri bir boyuta geçtiğimizi söylemek mümkündür. Çünkü bugün sanal ortamda oluşturduğumuz profiller oraya yüklediğimiz verilerle kendi gerçekliğimizden daha gerçek hale gelmiş durumdadır. Ayrıca bu profillerin farklı platformlarda yeniden üretilmesi gerçeği ortadan kaldırmakta ve kişiyi sadece bir veri, bir iz olarak görmektedir.

We are Social'ın 2020 Dijital Raporuna 2öre 4.57 Milyar internet kullanıcısı, 3,81 milyar sosyal medya ve 5,16 milyar mobil kullanıcı bulunmaktadır. Bu raporun sonucunda da görüldüğ̈̈ gibi internet kullanımı, sosyal medya kullanımı dünya geneline yayılmış ve benimsenmiştir. Baudrillard'ın işaret ettiği "gerçek" ile "sahte" arasındaki farkın yok olmaya başladığını bu raporun sonucuna göre yorumlamak zor olmayacaktır. Böylece insanlar dijital ortamda bir veri olmakta ve bu verilere göre değerlendirilmektedir.

Bu bağlamda sosyoloji açısından dikkate alınması gereken bir başka konu ise Toplum 5.0 kavramıdır. Bu kavram ise ilk kez 2013 yılında Japonya'da kullanılmıştır. Hızlı teknolojik gelişmelerin olumsuz algısına karşı toplum 5.0 kavramının yıkıcı değişimlere ve mevcut sorunlara faydalı olacağı savunulmaktadır. Toplum 5.0, teknolojik gelişmelerin topluma entegre edilmesiyle bütüncül bir şekilde hareket etmek olarak tanımlanabilir. (Saraçel ve Aksoy, 2020: 29). Endüstri 4.0'nn bünyesinde barındırdığı teknolojiler ve gelişim hızı ile toplumsal değişme sürecini karşılaştırdığımızda arada büyük bir dengesizlik ortaya çıkmaktadır. Bundan dolayı süreci sosyal politikalar ekseninde de ele alıp devrimin etkilerini yumuşatmak amaçlanmıştır.

Toplumların gelişme evrelerine baktığımızda avcı-toplayıcılıktan tarım toplumu modellerini devamında ise endüstri ve bilgi toplumu modellerini görmekteyiz. Toplum 5.0 ise bu sürecin en yeni modelini oluşturmaktadır. Süper akıllı toplum olarak adlandırılan bu toplum modelinde ise teknolojiden faydalanılarak bir bütün olarak

${ }^{2}$ Kaynak: https://wearesocial.com/digital-2020 
toplumun refaha kavuşması hedeflenmektedir. (Saraçel ve Aksoy, 2020: 29-30). Böylece yaşam kalitesi artacak ve daha sürdürülebilir bir fiziksel ve sosyal çevre oluşturulacaktır. Keidanren [2016: Japonya İş Federasyonu] tarafından gerçekleştirilen sunumda şimdilik Japonya'nın sorunları olan nüfusun yaşlanması, doğurganlığın azalması, hastalıklar ve terörizm ve çevresel sorunlar giderek diğer ülkelerin de sorunları haline geleceğini belirtmektedir. Dolayısıyla endüstri 4.0'ın gelişimi ve toplum 5.0'ın uygulanmasıyla birlikte bu sorunlarından üstesinden gelineceği düşünülmektedir. Böylece toplum 5.0 kavramı ekseninde geliştirilecek politikalarla teknoloji ile sosyal hayatın birlikte uyum içerisinde ilerlemesi hedeflenmektedir.

\section{SONUÇ}

Burada başta sorduğumuz soruyu tekrar sormak gerekirse: toplumun veri merkezli bir hale gelmesine nasıl yaklaşmalıyız? Bu soru gerçekten önemli bir soru ve sorundur. Bir taraftan ciddi güvenlik sorunları varken diğer taraftan verinin gittikçe gündelik hayatın merkezine gelmesi sorunu da vardır. Burada toplum olarak dikkat edilmesi gereken nokta bilinçli hareket etmektir. Görüldüğü gibi datalaşmaktan kaçmak imkansızdır. Ayrıca yeni çağ olarak adlandırdığımız endüstri 4.0 ile birlikte veri üretimi daha merkezi bir yerde durmaktadır. Bu açıdan veri üretmeye mesafeli davranmak dördüncü sanayi devrimine ve beraberinde getirdiği süper akıllı toplum olarak adlandırılan toplum 5.0'a geçme sürecini olumsuz etkilemesi oldukça muhtemeldir. Bu süreci geriden takip etmek veya uyum sağlayamamak bir toplumun yok olmasına neden olabilir. Çünkü günümüzdeki gelişim hızı dikkate alındığında toplumların geç kalma gibi bir şansının olmadığını görmekteyiz.

Verilerin kullanılması ve analiz edilmesinde önemli olan bir diğer nokta ise teknoloji-toplum iş birliğidir. Teknoloji alanında hızlı değişimler ve dönüşümler meydana gelirken aynı zamanda toplumsal yapının da bu süreci paralel bir şekilde takip etmesi gerekir. Aksi taktirde bir çatışma ve kriz ortamı kaçınılmazdır. Veri madenciliği üzerinde düşündüğümüzde daha önce bahsettiğimiz akıllı sistemler ve yeni sosyal düzen tamamen veri madenciliğine dayanmaktadır. İşleyiş mantı̆̆ı neticesinde kişilerden verilerin toplanması, analiz edilmesi ve bunun sonucunda kararlar üretilmesi bu sisteminin temelini oluşturmaktadır. Kişilerin bu sistemde verileri bilinçli bir şekilde kullanmaması tüm sistemin işleyişini aksatmaktadır. Veri kirliliğini veya eksikliğini bir fabrikanın üretim sisteminde ya da bir kentin güvenlik sisteminde meydana geldiğini düşünürsek ciddi sonuçlar doğuracaktır.

Burada dikkat çekilen nokta yeni çağda veri odaklı bir yaklaşımın hızla gelişmesidir. Metinde bahsedildiği üzere veri odaklı yaklaşım hayatın her alanında etkin bir rol oyarken insanların kontrolü ellerinden bırakmaması önemli bir konudur. Diğer bir ifadeyle insanların kendi ürettiği veriler tarafından belirlenmesi ve yönetilmesi durumu söz konusudur. Buna karşılık insanların ihtiyaca yönelik ve kontrolü bir veri paylaşımı yapması gerekir. Veri odaklı inşa edilen toplumsal yapıyı tamamen kabul etmek veya bu süreci tamamen reddetmek yerine ikisi arasında bir denge kurulması gerekmektedir. Daha açık bir ifadeyle bu süreç; teknolojik gelişmelerin farkında olmayı, çağı anlamayı, gelişimi görmeyi gerektirir. Aynı zamanda teknoloji çağında insan olmayı, insan kalmayı, süreç içerisinde aktif rol almayı da gerektirir. Böylece teknoloji ve toplumsal alanın birbirinden bağımsız hareket etmesi önlenecektir.

\section{KAYNAKÇA}

Baudrillard, J. (2018). Simülakrlar ve Simülasyon. (O. Adanır, Çev.). Ankara: Doğubatı.

Bernand Marr, 'Big Data Explained in Less Than 2 Minutes - To Absolutely Anyone’, (14 Kasım 2020). https://www.bigdatanews.datasciencecentral.com/profiles/blogs/big-data-explained-in-less-than-2-minutes-toabsolutely-anyone (Erişim Tarihi: 15 Şubat 2021)

Erdal, E. ve Papuşcuoğlu, T. (2018). Mühendislerin Anlam Dünyasinda Yapay Zekânın Yeri Ve Gelecek Beklentileri. Yayınlanmamış Metin.

Gençoğlu, A., Y. (2012). Kapitalizm, Kayseri Ekonomisi ve İş Adamları. (Yayınlanmamış Doktora Tezi) İnönü Üniversitesi, Sosyal Bilimler Enstitüsü, Malatya.

Harayama, Yuko (2017). Society 5.0: Aiming for a New Human-centered Society. Collaborative Creation through Global R\&D Open Innovation for Creating the Future: Cilt 6, Say1 66, 8-13. http://www.hitachi.com/rev/archive/2017/r2017 06/pdf/p08-13 TRENDS.pdf

Keidanren (Japan Bussiness Federation) (2016). Toward realization ofthe new economy and society. Reform of the economy and society by the deepening of "Society 5.0". Retrieved April 16, 2018 from http://www.keidanren.or.jp/en/policy/2016/029_outline.pdf

Marshall, G. (2020). Sosyoloji Sözlüğ̈̈. (O. Adanır ve D. Kömürcü, Çev.). Ankara: Bilim ve Sanat.

Sağıroğlu, S.., Demirezen M. U. ve Yazıcı, A. (2021). Yapay Zekâ ve Büyük Veri: Endüstri 4.0 ve Yapay 
Zekâ. Ankara: Nobel.

Saracel, N. ve Aksoy, I. (2020). “Toplum 5.0: Süper Ak1llı Toplum”, Social Sciences Research Journal, Cilt 9, Sayı 2, 26-34.

Schwab, K. (2020). Dördüncü Sanayi Devrimi. (Z. Dicleli, Çev.). İstanbul: Optimist.

Seker, S. E. (2015). Büyük Veri ve Büyük Veri Yaşam Döngüleri, YBS Ansiklopedi, Cilt 2, Sayı 3, 10-17.

Leonhard, G. (2018). Teknolojiye Karşı Insanlık. İstanbul: Siyah Kitap.

Tegmark, M. (2019). Yaşam 3.0: Yapay Zeka Çă̆ında İnsan Olmak. (E. C. Göksoy, Çev.). İstanbul: Pegasus.

Zencirkıran, M. (2015). Sosyoloji. Bursa: Dora.

We are Social, 'Digital Report 2020', (14 Kasım 2020). https://wearesocial.com/digital-2020 (Erişim Tarihi: 15 Şubat 2021).

\section{EXTENDED ABSTRACT}

The period we live in is witnessing rapid and effective changes. This change has started to develop especially in technological fields. However, even if these developments are concentrated in the industrial field, they are directly related to sociality and act with it. Because industry 4.0, the fourth industrial revolution, basically consists of information communication technologies and cyber-physical systems. In other words, the most important pillar of industry 4.0 is target communication and interaction. Therefore, individuals directly participate in this revolution consciously or unconsciously. It is "data" that includes social life in this process. In other words, data mining is the raw material of this process. When we think about data mining, it is possible to approach the situation in a pessimistic way in terms of the fact that people can be monitored and controlled by constantly recording. It can be considered as an important part of the new age, which will accelerate more than the tools related to data mining from the users and will take place manually from these devices. However, on the other hand, it can also be considered as the most important element of the new age, where data mining and technological developments accelerate and change and transformation will take place in every respect. So what is data mining in this article? How can the positive and negative aspects of data mining be evaluated? How should this process be approached from a sociological perspective? Questions like these will be answered. At the same time, the aim of this article is to examine the sociological effects of data mining and emerging technologies. In this respect, the study was organized in a theoretical framework based on the literature.

Data mining and data security issues are also based on big data and emerge thanks to big data. The basic idea behind the phrase 'Big Data' is that everything we do increasingly leaves a digital trace (or data) that we (and others) can use and analyze. In this age dominated by the Internet, the question of how much the data used is protected comes to the fore, just as our data is used in every situation. Because we use our data every minute and even add new ones to them. Although data mining is a gold mine for producers, it also creates privacy and security problems for consumers.

Generally, data mining is considered in terms of security and privacy. But sociologically she evaluates it on different grounds. First of all, it is possible to establish a relationship between the concept of panopticon, which Foucault reinterpreted, and data mining. In this respect, when data mining is evaluated, the continuous recording, recording and categorization of people's digital traces functions as a kind of panopticon. Being aware of this, people who are registered will constantly monitor themselves and act in accordance with the rules of power. Thus, instead of the mechanisms in which the power directly controls people, areas where it seems as if it does not control people, but where it exerts intense control and pressure, are developing. In addition, the point we need to pay attention to here is that this situation continues not only in the public sphere, but also in the private sphere. In other words, surveillance and control, which can only be carried out by the government in the public sphere, now continues very comfortably in private spheres as well. It is also possible to evaluate the dataization of society in terms of simulacra and simulation theory. Focusing on the television example, Baudrillard criticizes that even the most painful events become spectacle, and points out that an event, a pain, becomes just a simulacrum, and the truth and feelings disappear. When we evaluate it in terms of today, it is possible to say that we have moved to a more advanced dimension. Because the profiles we create in the virtual environment today have become more real than our own reality with the data we upload there. In addition, the reproduction and reproduction of these profiles on different platforms removes the truth after a while and sees the person as just a data and a trace.

In this context, another issue to be considered in terms of sociology is the concept of Society 5.0. Against the negative perception of rapid technological developments, it is argued that the concept of society 5.0 will be beneficial to destructive changes and existing problems. Thus, with the policies to be developed in line with the concept of society 5.0, it is aimed to advance technology and social life in harmony. The point that draws attention here is that a data culture should be acquired socially in the new age. Data culture is very important in the dataization of society because it is important in terms of not completely determining human activities and showing that people interfere with the situation. The formation of a data culture requires being aware of technological developments, understanding the age and seeing the development. At the same time, it enables to be human in the age of technology, to remain human and to take an active role in the process. Thus, it will be prevented that technology and social sphere act independently of each other. 